\title{
Potential functional roles of follistatin on bovine somatic cell nuclear transfer embryos
}

\author{
Kyung-Bon Lee $^{1 \dagger}$, Jae-Seok Woo ${ }^{2 \dagger}$, Bo-Myoung Lee ${ }^{1}$, Kang-Sun Park ${ }^{1}$, Kil-Woo Han ${ }^{1}$, Min Kyu Kim ${ }^{1}$ * \\ ${ }^{1}$ Department of Animal Science and Biotechnology, College of Agriculture and Life Sciences, Chungnam National University, Daejeon 305-764, \\ South Korea \\ ${ }^{2}$ Hanwoo Experiment Station, National Institute of Animal Science, RDA, Pyeongchang 232-950, South Korea
}

Received on 12 November 2013, revised on 26 November 2013, accepted on 17 December 2013

\begin{abstract}
To demonstrate that follistatin treatment enhances the efficiency of nuclear transfer (SCNT), cell allocation and preimplantational development were determined in bovine SCNT embryos in the present study. Treatment of activated SCNT embryos with $10 \mathrm{ng} / \mathrm{ml}$ follistatin significantly increased the proportion of blastocyst development compared to untreated SCNT embryos. In addition, an increase in trophectoderm (TE) cell numbers and relatively higher proportion of TE cells to total cells were observed, but the number of inner cell mass (ICM) cell and total cell numbers were not changed $(\mathrm{P}<0.05)$. No significant effect of other doses of follistatin was observed for the above endpoints. However, treatment with 1 and $10 \mathrm{ng} / \mathrm{ml}$ follistatin reduced the proportion of nuclear transfer blastocysts with an ICM ratio of $>60 \%$ relative to untreated nuclear transfer blastocysts at Day 7 . No significant effect of follistatin treatment on proportions of nuclear transfer blastocysts with ICM ratio of $20-40 \%$ or $40-60 \%$ was observed. Taken together, these results suggested that follistatin can be used to increase developmental competence of SCNT embryos in terms of cell allocation, particularly TE cells, during preimplantation stages, subsequently enhancing placentation and birth of live offspring.
\end{abstract}

Key words : Follistatin, Bovine, Blastocyst, Trophectoderm, Inner cell mass

\section{Introduction}

Poor oocyte competence contributes to infertility in humans and livestock species. Two well-defined bovine models of oocyte competence are the prepubertal oocyte and time to first cleavage models. In Vitro produced bovine embryos from prepubertal animals show a modest reduction in blastocyst formation (Revel et al., 1995; Damiani et al., 1996) and transfer of in vitro (Khatir et al., 1998) and in vivo produced bovine embryos (Armstrong et al., 2001) derived from oocytes of prepubertal animals results in reduced pregnancy success. Furthermore, in relatively earlier cleaved bovine embryos (30h post fertilization), blastocyst development rates are higher, compared to late cleaved

\footnotetext{
Kyung-Bon Lee and Jae-Seok Woo contributed equally to this work.

*Corresponding author: Tel: +82-42-821-5773

E-mail address: kminkyu@cnu.ac.kr
}

embryos (Plante et al., 1994; Lonergan et al., 1999).

During the initial cleavage divisions post-fertilization, embryonic development is supported by maternal mRNAs and proteins synthesized and stored during oogenesis which are critical for the interval between fertilization and the maternal-embryonic transition when transcriptional activity of the embryonic genome becomes robust at the 8-16 cell stage in cattle (Telford et al., 1990; De Sousa et al., 1998). Thus, time to first cleavage of early bovine embryos is likely significantly influenced by differences in oocyte derived mRNA and proteins. However, the cloning/nuclear transfer technology for propagation of valuable livestock species, generation of transgenic animals, therapeutic cloning and research purposes is currently limited by low efficiency. Thus, we need to modify compositions in culture medium or develop methods for increasing the proportion of SCNT 
embryos that develop to the blastocyst including the number of trophectoderm (TE) cells with higher developmental competence, leading to an increase in live births from embryos.

It has been reported that follistatin plays a functional role in regulation of early embryogenesis in bovine (Lee et al., 2009) Especially, follistatin supplementation in the culture medium increased time to first cleavage, proportion of blastocyst, and total and trophectoderm cell numbers of blastocyst. In the present study, we also used bovine model to test whether follistatin plays a functional role in somatic cell nuclear transfer embryo.

\section{Materials and Methods}

\section{Chemicals and media}

Unless otherwise stated, all chemicals used in the present study were purchased from Sigma-Aldrich Chemical Co. (St. Louis, MO, USA). The medium used for oocyte washing was Hepes-buffered Hamster Embryo Culture Medium (H-HECM). The basic medium used for oocytes maturation was Medium 199 supplemented with $0.2 \mathrm{mM}$ sodium pyruvate, $5 \mathrm{mg} / \mathrm{ml}$ gentamicin sulfate, $6.5 \mathrm{mM}$ L-glutamine, $1 \mathrm{mg} / \mathrm{ml}$ bovine $\mathrm{LH}$ (Sioux Biochemical, Sioux Center, LA), $1 \mathrm{mg} / \mathrm{ml}$ bovine FSH (Sioux Biochemical), $1 \mathrm{mg} / \mathrm{ml} 17$-estradiol, and 10\% v/v defined FBS (Hyclone, Logan, UT). The C4 and BO medium (Proprietary medium, Cyagra Inc., USA) were used for somatic cell nuclear transfer (KohanGhadr et al., 2008). The basic medium used for culture of embryos was C4 and C5 medium (Kohan-Ghadr et al., 2008).

Preparation of Oocytes, Maturation and Enucleation Cumulus-oocyte complexes (COCs) were aspirated from small antral follicles of 2-7 $\mathrm{mm}$ in diameter using an 18-gauge needle and 60-70 $\mathrm{mm} \mathrm{Hg}$ of negative pressure in bovine ovaries obtained at a local abattoir. After washing of COCs with H-HECM, only oocyte with more than 3-4 layers of intact and unexpanded cumulus cells were selected. A group of 50 COCs was introduced into 4-well dishes containing $400 \mathrm{ml}$ of maturation medium, which had previously been equilibrated in an atmosphere of $5 \% \mathrm{CO}_{2}$ in air at $38.5^{\circ} \mathrm{C}$ for at least $2 \mathrm{~h}$. The COCs were then cultured for $18 \mathrm{~h}$ at $38.5^{\circ} \mathrm{C}$ under the same atmospheric conditions. After maturation, cumulus cells were removed from the oocytes by $0.1 \%$ hyaluronidase treatment, and oocytes with extruded first polar bodies were selected for enucleation. The oocytes were stained with $0.5 \mathrm{mg} / \mathrm{ml}$ Hoechst 33342 in C4 medium for $20 \mathrm{~min}$ at $38.5^{\circ} \mathrm{C}, 5 \% \mathrm{CO}_{2}$ in air. All manipulation was performed in $\mathrm{BO}$ medium supplemented $7.5 \mathrm{mg} / \mathrm{ml}$ cytochalasin B. Both nuclei and polar body were removed by aspiration using an enucleation pipette.

\section{Somatic cell nuclear transfer}

Donor cells were cultured in Dulbecco's modified minimum essential medium (DMEM; Gibco BRL, USA) supplemented with 20\% FCS (Hyclone, USA) and antibiotic-antimycotic (Gibco BRL, USA) in an atmosphere of $5 \% \mathrm{CO}_{2}$ in air at $38.5^{\circ} \mathrm{C}$ until these cells reached approximately 70\% confluency. The cells were disaggregated by trypsin-EDTA treatment prior to nuclear transfer. A single donor cell was injected into the perivitelline space of each enucleated oocyte. NT couplets were activated by $5 \mathrm{mM}$ ionomycin in $\mathrm{BO}$ medium supplemented with $0.1 \%$ fatty-acid-free BSA (BSA-FAF) for $4 \mathrm{~min}$. After activation, nuclear transfer couplets were immediately fused in sorbitol fusion medium by a single electric pulse (15 ms each, 1.8-2 $\mathrm{kV} / \mathrm{cm}$ ). This was followed by incubation of NT embryos in C4 medium supplemented with $5 \mathrm{mg} / \mathrm{ml}$ cytochalasin B and $10 \mathrm{mg} / \mathrm{ml}$ cycloheximide for $6 \mathrm{~h}$. At the end of incubation, NT embryos were washed and transferred to culture medium. Untreated parthenogenetic embryos were included as quality control for oocytes. 


\section{In vitro culture}

The activated nuclear transfer and parthenogenic embryos were cultured in the presence or absence of 1, 10 and $100 \mathrm{ng} / \mathrm{ml}$ follistatin for initial $72 \mathrm{~h}$. Embryos reached at the 8-16 cell stage were separated and cultured in C5 medium until Day 7. Proportion of embryos developing to the blastocyst stage is also depicted. The inner cell mass (ICM) and the trophectoderm (TE) cells of Day 7 blastocysts obtained were counted by differential staining.

\section{Differential staining of ICM and TE}

The numbers of trophectoderm (TE) versus inner cell mass (ICM) cells and total cell numbers were determined by cell counts on differentially stained embryos. Briefly, the zonae pellucidae (ZP) of Day 7 blastocysts were removed by $0.5 \%$ pronase, and $\mathrm{ZP}-$ free blastocysts were washed in H-HECM. These blastocysts were then incubated in a 1:5 dilution of rabbit anti-pig whole serum (P-3164) for $1 \mathrm{~h}$. After three times washing for each $5 \mathrm{~min}$, the blastocysts were incubated in a 1:10 dilution of guinea pig complement ( $\mathrm{S}-1639)$ for $1 \mathrm{~h}$. A final concentration of $10 \mathrm{mg} / \mathrm{ml}$ propidium iodide (PI) was added to the complement solution. After washing again in H-HECM, they were mounted between slide glass and cover glass, and examined under Nikon inverted microscope using UV light. Total number of blastocysts introduced for differential staining was 22, 17, 23, 26 and 15 for parthenote, untreated control, 1,10 and $100 \mathrm{ng} / \mathrm{ml}$ follistatin, respectively.

\section{Statistical analysis}

Data were analyzed using one-way ANOVA. For the embryos culture experiments, data were subjected to an arc-sin transformation, and the transformed values were analyzed using one-way ANOVA. When
ANOVA revealed a significant effect, the treatments were compared by Fisher's Protected Least Significant Difference (PLSD) test.

\section{Results}

To demonstrate that follistatin treatment enhances the efficiency of nuclear transfer, the effects of follistatin supplementation on cell allocation and blastocyst development of nuclear transfer embryos was determined.

Due to defects in placentation and blastocyst cell allocation characteristic of SCNT embryos (presumably leading to high rates of pregnancy loss), this experiment was conducted to determine the effects of follistatin supplementation on development of SCNT
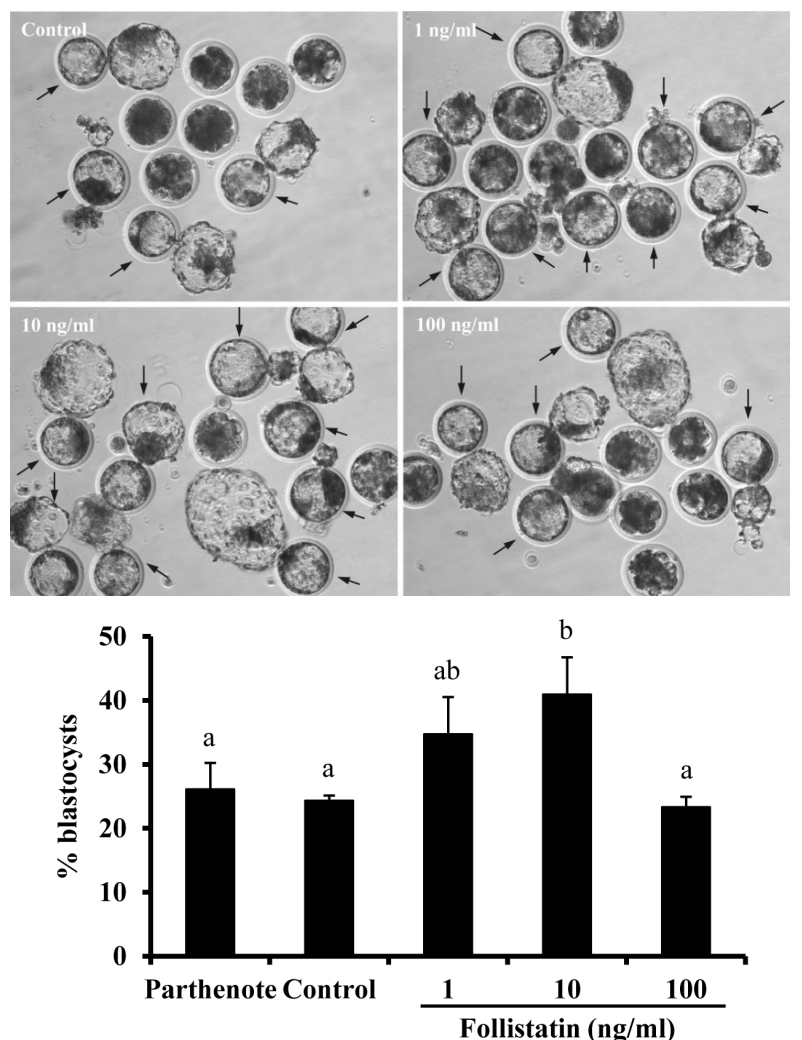

Fig. 1. Effect of follistatin treatment on development of nuclear transfer embryos to the blastocyst stage. The results are expressed as mean \pm SEM of the data collected from four replicates. Values with different superscripts across treatments indicate significant differences $(\mathrm{p}<0.05)$. Red arrows indicate SCNT-derived blastocysts. 

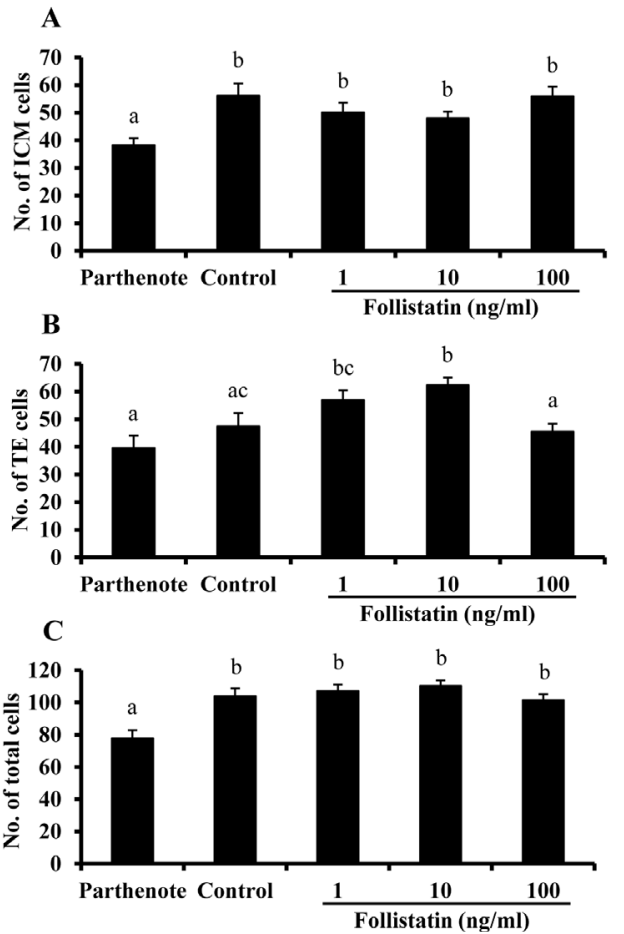

Fig. 2. Effect of follistatin treatment on cell allocation in nuclear transfer blastocysts. The effect of follistatin treatment on number of (A) inner cell mass, (B) trophectoderm and (C) total cells is depicted. The values are expressed as mean \pm SEM of the data collected from four replicates. Values with different superscripts across treatments indicate significant differences $(\mathrm{p}<0.05)$.
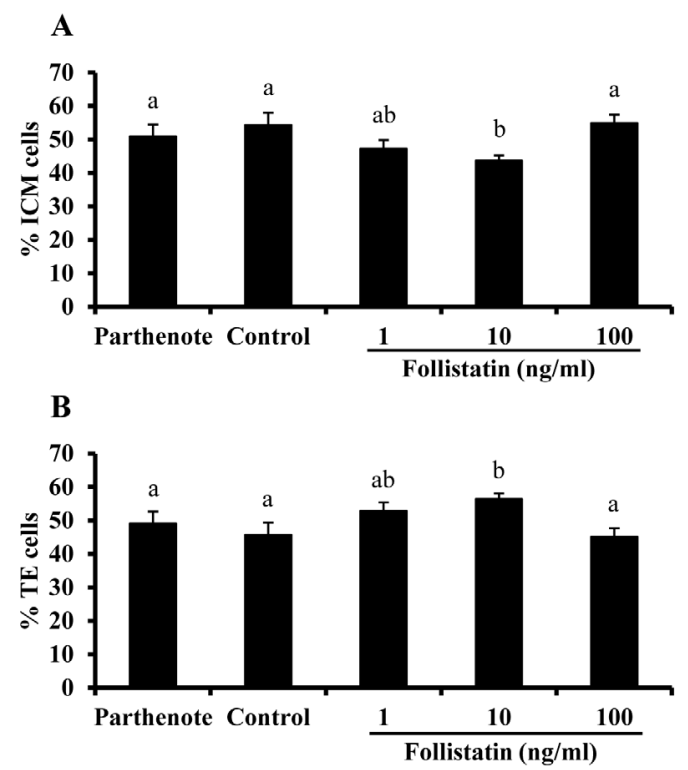

Fig. 3. Effect of follistatin supplementation on \% ICM cells and TE cells in blastocyst stage embryos generated via nuclear transfer. Effect of follistatin supplementation on (A) the proportion of ICM cells versus total cells and (B) the proportion of TE cells versus total cells are depicted. The values are expressed as mean \pm SEM of the data collected from four replicates. Values with different superscripts across treatments indicate significant differences $(\mathrm{p}<0.05)$.
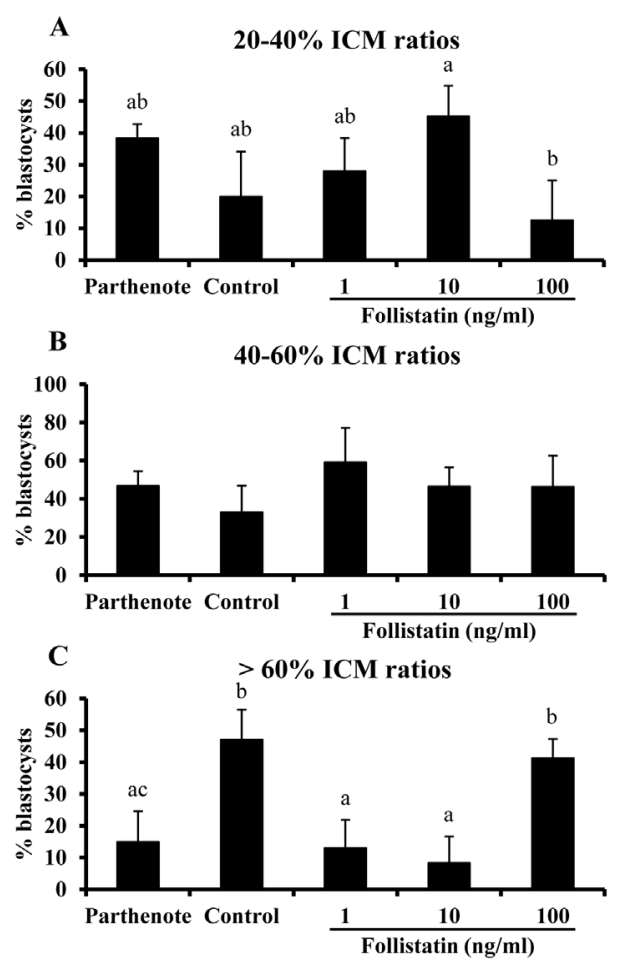

Fig. 4. Effect of follistatin supplementation on the proportion of nuclear transfer embryos reaching blastocyst stage with different ICM/total cell ratios (ICM ratio) reflective of embryo quality. The proportions of nuclear transfer blastocysts with ICM ratio of (A) $20-40 \%$, (B) $40-60 \%$ and (C) $>60 \%$ is depicted. The values are expressed as mean \pm SEM of the data collected from four replicates. Values with different superscripts across treatments indicate significant differences $(p<0.05)$.

embryos to the blastocyst stage and on blastocyst cell allocation. Treatment with $10 \mathrm{ng} / \mathrm{ml}$ follistatin significantly increased the proportion of nuclear transfer embryos developing to the blastocyst stage relative to untreated nuclear transfer embryos $(p<0.05)$ (Fig. 1). Treatment with $10 \mathrm{ng} / \mathrm{ml}$ follistatin significantly increased numbers of TE cells and proportion of TE cells to total cells and decreased the proportion of ICM cells to total cells relative to untreated SCNT embryos $(p<$ $0.05)$, but not significantly affected numbers of ICM and total cells (Fig. 2). No significant effect of other doses of follistatin was observed for the above endpoints. However, treatment with 1 and $10 \mathrm{ng} / \mathrm{ml}$ follistatin reduced the proportion of day 7 nuclear transfer blastocysts with an ICM ratio of $>60 \%$ relative to untreated nuclear transfer blastocysts (Fig. 3). No 
significant effect of follistatin treatment on proportions of d 7 nuclear transfer blastocysts with ICM ratio of 20-40\% or $40-60 \%$ was observed (Fig. 4).

\section{Discussion}

It was previously demonstrated that follistatin is a marker of egg quality in cattle (Lee et al., 2009). The effects of endogenous follistatin on early embryonic development of in vitro fertilized bovine embryos were examined and stimulatory effects on development to the blastocyst stage and number of TE cells/ embryo quality were observed. TE cells combine with the ICM-derived ectraembryonic membranes to form the fetal placenta after pregnancy. Both ICM and TE cell lineages are essential for embryonic and fetal survival (Hardy et al., 1989) as well as embryo quality (Goo et al., 2002). Given the stimulatory effects on blastocyst development and embryo quality (TE cells) observed and the observation that the number of TE cells and quality of nuclear transfer embryos is believed responsible for the less than 5\% efficiency of generation of lives offspring, the effects of follistatin on development of nuclear transfer embryos to the blastocyst stage and numbers of $\mathrm{TE}$ cells in such embryos was examined.

In the present study, follistatin can enhance the proportion of blastocysts with ICM ratio of $20-40 \%$ even though there are no significant differences compared to control. It has been reported that embryos with ICM ratio of $20-40 \%$ are presumed to be higher quality because $>80 \%$ of in vivo-derived blastocysts were classified into this category in previous studies (Goo et al., 2002). Our result suggests that follistatin can increase the quality of in vitro produced blastocyst.

Results indicate a pronounced stimulatory effect of follistatin on development of nuclear transfer embryos to the blastocyst stage, indicating follistatin treatment results in more transferable embryos. Results also indicate that follistatin treatment significantly enhances embryo quality (number of TE cells) and results in a greater proportion of live offspring born after transfer of nuclear transfer embryos.

Collectively, the results of the above studies demonstrate that follistatin treatment can be used to increase developmental competence of nuclear transfer embryos to the blastocyst stage and enhance blastocyst cell allocation in favor of TE cells for enhancing placentation and ultimately birth of live offspring.

\section{Acknowledgements}

This work was supported by the grant from Nextgeneration BioGreen 21 program (Grant No. PJ009624) funded by the Rural Development Administration, South Korea.

\section{Reference}

Armstrong DT. 2001. Effects of maternal age on oocyte developmental competence. Theriogenology 55:1303-1322.

Damiani P, Fissore RA, Cibelli JB, Long CR, Balise JJ, Robl JM, Duby RT. 1996. Evaluation of developmental competence, nuclear and ooplasmic maturation of calf oocytes. Molecular Reproduction and Development. 45:521-534.

De Sousa PA, Watson AJ, Schultz GA, Bilodeau-Goeseels S. 1998. Oogenetic and zygotic gene expression directing early bovine embryogenesis: a review. Molecular Reproduction and Development. 51: 112-121.

Goo DB, Kang YK, Choi YH, Park JS, Kim HN, Oh KB, Son DS, Park H, Lee KK, Han YM. 2002. Aberrant allocations of inner cell mass and trophectoderm cells in bovine nuclear transfer blastocysts. Biologly of Reproduction. 67:487-492.

Hardy KH, Handyside AH, Winston RML. 1989. The human blastocyst: cell number, death and allocation during late preimplantation development. Development 107:597-604.

Khatir H, Lonergan P, Touzé JL, Mermillod P. 1998. The characterization of bovine embryos obtained from prepubertal calf oocytes and their viability after non surgical embryo transfer. Theriogenology 50:1201-1210.

Kohan-Ghadr HR, Lefebvre RC, Fecteau G, Smith LC, Murphy BD, Suzuki Junior J, Girard C, Hélie P. 2008. Ultrasonographic and histological characterization of the placenta of somatic nuclear transfer-derived pregnancies in dairy cattle. Theriogenology 69:218-230.

Lee KB, Bettegowda A, Wee G, Ireland JJ, Smith GW. 2009. 
Molecular determinants of oocyte competence: potential functional role for maternal (oocyte-derived) follistatin in promoting bovine early embryogenesis. Endocrinology 150 : 2463-2471.

Lonergan P, Khatir H, Piumi F, Rieger D, Humblot P, Boland MP. 1999. Effect of time interval from insemination to first cleavage on the developmental characteristics, sex ratio and pregnancy rate after transfer of bovine embryos. Journal of Reproduction and Fertilty. 117:159-167.

Plante L, Plante C, Shepherd DL, King WA. 1994. Cleavage and $3 \mathrm{H}$-uridine incorporation in bovine embryos of high in vitro developmental potential. Molecular Reproduction and Development. 39:375-383.

Revel F, Mermillod P, Peynot N, Renard JP, Heyman Y. 1995. Low developmental capacity of in vitro matured and fertilized oocytes from calves compared with that of cows. Journal of Reproduction and Fertilty. 103:115-120.

Telford NA, Watson AJ, Schultz GA. 1990. Transition from maternal to embryonic control in early mammalian development: a comparison of several species. Molecular Reproduction and Development.26:90-100. 